\title{
Policy and Practice: Recursive Learning from Crisis
}

\author{
Dominic Elliott ${ }^{1}$ \\ University of Liverpool \\ cinimod@liverpool.ac.uk
}

\author{
Allan Macpherson \\ University of Liverpool \\ a.macpherson@liverpool.ac.uk
}

\author{
OLKC Conference \\ Amsterdam \\ 26-28 ${ }^{\text {th }}$ April 2009
}

\begin{abstract}
The origins of this paper lie in the observation that organizations, frequently, fail to learn from crisis. Drawing from theory in field as diverse as actor network, crisis management, institutional and organizational learning the paper considers the case of the crisis triggered by severe flooding in the UK and Gloucestershire in particular. In this case the available artefacts that were developed prior to the crisis (and afterwards) framed and stabilized a particular set of connections. In this event, the data suggest rigidity amidst a relatively inadequate response. The inadequacy of the response was more marked given the award of Beacon Status to Gloucestershire County Council for its emergency preparedness some months before the extreme weather event. The paper suggests that learning in and from experience, prepares us only to replay what we have learned in order to make sense of and enact practice in a similar scenario; that is, to use that experience to make sense of unfolding events. It is only when a breakdown of coping occurs, when things do not go as intended, that we become aware of the inadequacy of our established practices. We should not be surprised when the lessons we have learned fail to prepare us for unforeseen events, or even when, in similar circumstances, but with different technologies or people involved, outcomes during and after crises are disappointing.
\end{abstract}

Keywords: Risk Management, Learning from Crisis, Artefacts, Institutionalization

\footnotetext{
${ }^{1}$ Management School, University of Liverpool, Chatham Street, Liverpool, L69 7ZH
} 


\section{Policy and Practice: Recursive Learning from Crisis}

\subsection{Introduction}

Although crisis events have been the subject of extensive investigations, it is evident that organizations often fail to learn effectively. One contributory factor for this failure may be the fragmented nature of our understanding, and the resulting piecemeal conceptualisation of the process. A second concern is the confusion of learning with identifying lessons, especially within the policy literature. For example, Birkland (2006), who was concerned with $9 / 11$ and environmental disasters/crises, such as oil spills or radioactive hazards, suggested that 'enacted legislation and regulations' provided evidence of policy change or movement indicating that some sort of learning had occurred'. However, critiquing such a narrow view of learning, and seeking to redress the fragmentation of research in this area, Elliott (2008) used Turner's (1976) notion of cultural readjustment and defined learning as: 'the flow of fresh understandings into new organizational operating norms and practices.' The processes of organizational learning from crisis, he argued, should be conceptualised as knowledge creation at policy and micro levels, its transfer through regulation and field configuring events, amongst other means, and ultimately through assimilation, evident in individual and organizational behavioural changes. A key gap identified by Elliott (2008), was the scant attention given to the processes of knowledge transfer.

This paper is concerned with the processes by which knowledge transfer occurs; that is the processes whereby lessons from crises are translated into artefacts including policies, practices, rules and 'established best practice' as a means by which learning may become institutionalized. At the very least, previous learning is represented in these artefacts which partially construct the landscape on which future events will occur. After all, organizations are a 'nexus of practices and material arrangements' (Schatzki, 2005: 465), and practices in organizations are structured around, or against rules, processes and systems of organizing designed by an organizational elite (Child, 1972). Within practice-bundles, artefacts - such as tools, technologies, rules, systems, procedures, targets, objectives, and so on-are representations of existing states of affairs that symbolize existing knowledge of how to do things (Engeström and Blackler, 2005). These artefacts also anchor relationships between individual actors within an activity system (Taylor and Robichaud 2004), and they frame and stabilize the meaning of activity such that actors can calculate the validity and efficacy of their (and others') performance (Callon, 1999). In this way, such artefacts, or objects are an integral part of social order and activity. Whether these rules are followed, or not, and whether technology creates opportunities to connect with others in our work practices, they influence the social order of activity and can create barriers between, or ways of integrating with, others. As such, it is suggested that policies represent only current understandings of what constitutes 'best practice' following learning from crisis, and their usefulness may be ineffective, or even hinder recovery, during the dynamic and unpredictable events revealed at times of crisis (Smith and Elliott, 2007). Artefacts that denote past learning are dormant unless they are actually put into practice, and their usefulness may be limited given that they represent learning from events that occurred in a particular socio-historical context.

That limited attention has been given to the intersection between theories of organizational learning and institutions (Haunschild and Chandler, 2008) is notable given the emphasis within institutional theory concerning the adoption of new knowledge and learning within the evolution of fields (for example, Lampel and Meyer, 2008). The aim of this paper 
is to bring together institutional literature that deals with learning from crisis, with dynamic views of organizational processes that propose a processual view of learning and organizing. The specific contribution is to re-conceptualise the crisis learning processes and to suggest a future research agenda. The paper uses data from a major flooding event that occurred in the UK during the summer of 2007. While three regions were hit particularly badly, the main source of the data is from the episode that occurred in Gloucestershire. The paper proceeds with a review of the literature on organizational learning from crisis, which is followed by a discussion on the nature of practice and the nature of collective action, in situ. Thereafter, we present our data and methods and, in our analysis, we propose an alternative framework for conceptualizing learning in, from, and for, crisis. It is envisioned as a situated, dynamic, partial and recursive process. Each iteration of learning provides the landscape for future events, but enacting that learning successfully is difficult given the unpredictable nature of crisis, and the variety of contexts and people that interpret such ambiguous situations.

\subsection{Institutionalizing Learning From Crisis}

Within the context of organizational learning from crisis, Elliott (2008) has argued that underlying many studies, implicitly, is a view of learning that is temporally linear. This 'model' of the process assumes that knowledge is acquired, disseminated and absorbed into the routines or organizations and individual practices. A similar process is envisioned for 'learning for crisis' where standards are prescribed to encourage 'best' and 'better' systems and practice within organizations. Organizational learning, in both cases is concerned with adopting the prescriptions legitimated either through public inquiries or through bodies such as ISO, the BSi or in the case of the UK local government, Beacon Status. Emerging from this critique was a tentative model of a synchronous view of organizational learning from crisis (figure 1), one which is more fully developed below.

\section{< Insert figure 1 here >}

Figure 1 seeks to capture the synchronous interplay between policy, institutional field and organizational levels in learning after crisis. Knowledge, argued Elliott (2008) was created at all levels and, potentially, simultaneously. However, the literature dealing with organizational learning from crisis has focused upon either the levels of public policy (for example, May, 1992; Birkland, 1997, 2006; Boin, McConnell and t'Hart, 2008), or organization (Carroll, Rudolph and Hatakenaka, 2002; Jones and Cox, 2005; Elliott and Smith, 2006). The role of artefacts such as policies and 'established best practice' as institutionalising forces has received little consideration within studies of organizational learning and crisis. This is a surprising omission given the emergence of the so called 'Audit Society' (Power, 1997) and the rise of bodies and professions monitoring and checking organizational activities, systems and procedures to ensure their accountability. Focusing upon risk management in particular, Power (2007) identified the desire for public transparency as a driver for the dissemination of within UK government departments. However, a key weakness, suggested Power, was that the emphasis of guidance was with process rather than content, resulting in standardisation to the detriment of cultural context. A central tenet of institutional theory, exemplified by Drori, Meyer and Hwang (2006), is that organizations are subject to explicit and implicit norms and standards, emerging from professionalized or scientific knowledge' of 'appropriateness.' In their seminal work Tolbert and Zucker's (1983) identified the drive to imitate 'legitimised templates' as a key driver of diffusion. Although they are rarely statutory requirements, standards, it may be seen, provide an almost legal, 'legitimised', template. As such they may be viewed of as a potential 
stimulus for innovation, alongside those typically identified within institutional theory technological change and market forces.

The emergence of standards, guidelines and new policies may reflect a growing view of institutional fields as fragmented and contested in character (for example, Zilber, 2002; Lounsbury, 2007). Indeed, the cultural challenge triggered by a crisis may provide an important source of opposition to the forces encouraging isomorphism. The presence of standards implies a distinction between those organizations where practices are legitimate within a field and those where they are not. In this way the emergence of standards may be seen as a key field configuring mechanisms of the 'Audit Society'. Greenwood et al. (2008) have argued for the inclusion of regulatory frameworks only where they embodied 'taken-forgranted', 'explicitly identified' norms and values. A careful reading of this position may distinguish between imposed regulations and those generated from within an institutional field; the latter case perhaps being typical of many standards which secure legitimacy through a collaborative development of field members. Standards come to represent collective wisdom and provide a mechanism for its diffusion through the pressing out of differences between forms, as some consensus of what is institutionally acceptable develops (DiMaggio And Powell, 1983).

Increasingly researchers using an institutional theory approach have highlighted the influences of an organization's own meaning systems as shapers of new practice adoption in contesting a simple institutional determinist perspective (e.g. Schein, 1985; Cohen and Levinthal, 1990; Greenwood et al. 2008). In this way institutional theory may be, in parts, shifting towards organizational learning perspectives, such as that advocated by Crossan et al. (1999) amongst others. Here lies what Love and Cebon (2008: 240) identified as the 'tension between conformity and distinctiveness'. Indeed at the level of individuals, groups and organizations the potential for crisis to trigger a challenge to established assumptions and symbols and create a fertile context for learning is well established (Smith and Elliott, 2007). However, the establishment of new standards, legitimised by virtue of their authors, sponsors, supply chain position or other source of credibility may also trigger change. Such standards, whether or not they are an outcome from the lessons identified from an inquiry into crisis, are efforts to codify lessons learnt into a format that may be transferred to organizations. Typically studies of learning from crisis at the level of individual and group, argued Elliott (2008), have dealt with either facilitators (see for example, Cox and Jones) or more often, barriers (see for example, Smith and Elliott, 2007).

In some ways the contexts of learning 'for' and 'from' crisis respectively, both contrast with the typical focus of institutional theory with the emergence and evolution of a new fields (for example, Lampel and Meyer, 2008) and share a redefining of what is apt and legitimate. Legitimacy in the context of learning from crisis may arise from the appointment of appropriate experts as principal investigators leading an inquiry held in public. Elliott's (2008) critique of such processes identified how such efforts to acquire knowledge were open to deliberate manipulation or unintended distortion and that their findings were thus, suspect. Legitimacy in the context of learning for crisis, in this case a new British Standard in Business Continuity Management and Local Authority Awards, arose from a perception that associated guidelines had been developed by experts. What is unclear is how relevant experts were identified and the evidence base on which this standard and award were developed.

In summary, an institutional perspective provides a means for considering transorganizational structures and the roles of field configuring mechanisms in spreading new normative structures. It provides a context for considering the dynamic interplay between 
meaning systems at organization and field levels respectively, an area largely neglected (Wiseman, 2007). Institutional theory provides a focus by which knowledge may be transferred between the levels of policy and organizations, respectively.

\subsection{Enacting Responses to Crises: Artefacts and Social Practices of Organizing}

Institutional theory, then, provides a way of understanding how the landscape is set and within which organizational level events are conducted. As noted above, the lessons learned are often captured in new standards, policies or protocols that guide behaviours, or set out norms of 'best practice' in organizations and institutional fields. In that way, learning is captured and articulated in documents or 'artefacts' that represent past learning, which can be shared easily. It is these artefacts that provide the framework within which action to cope with future crises is conducted. Learning for crisis means that standards, such as those of Business Continuity Management, are likely to be enacted in response to some future event. It is here that the dynamic nature of learning in, from, and for crisis is apparent.

Much of what occurs during a crisis is the result of individuals, or individuals operating in groups that represent organizations and institutional fields, responding to events that are dynamic, ambiguous and confusing. In doing so, they draw upon their own repertoire, their human capital, accumulated over time. As Weick (1995) points out, whilst existing practical and theoretical knowledge helps with the integration of new knowledge it also shapes how individuals adapt to ambiguity. Enactment involves not only the action taken, but the sensemaking process of 'action, activity and creating that lays down the traces that are interpreted and then reinterpreted' (Weick, 1995: 13). Enactment may be settled into new accounts, versions or expectations, which then become part of the continually unfolding context of action (Weick, 1988). Thus, this enaction of practice is not just about knowing how to do things, but it involves the application of rules and norms previously defined that prescribe the limit of what should be done (Schatzki, 2005). In other words, because existing stocks of human capital are the basis of sense-making resources, such prior knowledge has the potential to constrain the ability of individuals to conceptualize alternative actions and practices, and even influences whether others might view any such actions as legitimate. Knorr Cetina (1999) describes such amalgams of past experience and material entities that make up a given field as 'epistemic cultures'. These are the behavioural, symbolic and material arrangements within, and against which, knowledge and expert practice are judged: 'they create and warrant knowledge' (ibid: 1 ).

Taking this perspective, policy, procedures, rules and norms represent accounts of past learning, but they only become real, for better or worse, through purposive action (Schatzki, 2005). Lessons learned from previous crises only become meaningful when they are put into practice; they have to be translated and used to make sense of new situations and enacted in order to manage an unfolding scenario. However, despite the fact that most organisations and institutions attempt to capture learning in manuals, organisational charts, processes, policies, training programmes and job descriptions, this cannot capture the vast range of tacit knowledge generated in practice. Brown and Duguid (1991) ably demonstrate that attempts to deconstruct and document complex working practices often fail because actual practices differ from those recorded in such learning repositories. Documented procedures provide a useful point of reference, but they cannot capture the complex unfolding nature of work and the tacit practices employees develop over time as they solve practical problems in their day-to-day employment. Moreover, new employees pick up such tacit knowledge through participation and not just by reading documents. While learning may take 
place within an organizational practice-based community - such as a project team or a traditional work group - knowledge and learning boundaries, and in some cases the tacit nature of that learning, may also restrict the sharing and transfer from one context to another (Scarbrough et al., 2004). Taking this perspective on knowledge and learning, one can see that learning from crisis to establish 'best practice' might provide only a partial account of that practice, but also how 'best practice' may not be suitable or adaptable to an alternative context.

As Schatzki (2005) and others make clear, however, practice also involves engagement with artefacts, technologies and material arrangements that shape, and are shaped by organization. Artefacts or technologies, both symbolic and material, are considered to embody and represent shared understanding actively constructed and stabilized through purposive engagement in collective activity (Engeström and Blackler, 2005). However, those technologies are not fixed entities. Rather they are (re-)constituted as people in and between organizations engage in everyday, situated practices that occur as they use their technologies or artefacts in unique circumstances (Orlikowski, 2000). Indeed, the technologies themselves can become the locus of activity: the devices through which people both orientate their relationships and through which new relationships and technologies emerge (Taylor and Robichaud 2004). Callon (1999), for example, shows how technology has fundamentally reconfigured and reconstituted practices in global markets, changing the norms and geographical space of interactions and relationships; it is technology that makes this these trading zones possible, but they also shape the possible range of acceptable conduct by the actors within them. The introduction of new technologies, artefacts or objects thus disrupts accepted relationships and existing practices by bringing into view alternatives and differences (Bechky, 2003). They also help to establish new social connections between people and can translate meanings between them (Latour, 1999; Knorr Cetina, 2001; Kellogg, 2006). Artefacts, may guide or circumscribe meaning within a particular community, but, if they are flexible enough, they also help to translate meaning between different epistemic worlds, such as across organizational boundaries (Star and Greisemer, 1989; Carlile, 2002). Indeed technologies in this view will continue to be central to activity, but, when existing material arrangements cease to be of value, or fail to support desired ends, they will be modified or discarded (Orlikowski, 2002).

This type of practice-based understanding proposes a view of artefacts (material and non-material) as being central to organization, and not just a product of it since they: stabilize particular sets of understandings; (re-)constitute associations and relationships between actors; they translate meaning between actors in different epistemic worlds; and they are (re-) configured or changed when they fail. This view of organizing has profound implications for learning from crisis. What is being suggested here is that technologies, artefacts, routines cannot easily be transferred from one context to another. Rather, because they inscribe the knowledge gained from the historical set of contexts and relationships, they represent and have been developed by people with a particular understanding of those contexts. Used in different contexts, and by different people with different levels of experience, skills and perhaps even motives, outcomes are not certain. People learn through people practising their craft and embedding what they have learned in the routines they use to cope in organizations (Antonacopoulou, 2008). The more experiences they have, and the more difficulties they have faced, the wider is their likely repertoire of sensemaking tools (Weick, 1995). Coping with crisis cannot just be about deliberately acquiring a set of 'transmitted' abilities, since to achieve competent practice depends on becoming better by doing. 


\subsection{Methods and Data}

The paper focuses upon one UK local authority's preparation for, and response to, the major flooding of the summer of 2007, but this is set within the context of a wider flood crisis that affected a number of regions within the UK. The Local Authority of Gloucestershire County Council, the region that is the primary focus for this study, had previously attained 'Beacon' status. This award was in recognition of excellence in Emergency Planning, especially for their processes of Business Continuity Management (BCM). The purpose of the Beacon Scheme was to disseminate 'best practice' in service delivery across local government. A widely used definition of BCM is that it:

"is a holistic management process that identifies potential impacts that threaten an organisation and provides a framework for building resilience and the capability for an effective response that safeguards the interests of its key stakeholders, reputation, brand and value creating activities.” [BCI, 2007]

An award under the Beacon Scheme may be seen to play an important part in institutionalising best practice within local government. On 20th March 2007 Gloucestershire's local government agencies achieved the prestigious Beacon Status for their BCM systems, thereby recognising the way they planned for, and responded to, major emergencies. In analyzing how this local authority coped with the crisis, data for the paper are drawn from a number of sources. As well as interviews with the Head of Emergency Management Service within Gloucestershire County Council, publicly available information, such as newspaper reports, the official documents and report from a public inquiry, the Pitt Report (2008), and the Garnham Report (2007) a performance review of Gloucestershire County Council specifically commenting on its performance following the crisis. The findings of the Garnham (2007) and Pitt (2008) Reports themselves were based upon extensive written and verbal submissions, visits to affected areas and consideration of other countries' experiences. In addition, the paper draws upon news reports and interviews with personnel from Gloucestershire, both prior to and following the flooding.

In analyzing the data, we were sensitive to how issues were described, problems overcome, or not, and how people described the activities in which they were involved. We drew from institutional theory, organizational learning and practice-based theories to identify and categorize themes in the data. Informed by this theoretical discourse, we were alert to the levels at which decisions and actions are taken, and the interactions between organizations, groups and individuals (the 'social associations') through which practices were enacted. Here we were not only concerned with who was doing what, and with whom, but we were also interested in why particular activities were conducted, and what principles guided actions. So for example, where there is evidence of routines, norms, processes or standard practices being followed, we noted whether this was a codified practice, or one which was more dynamic and emerging from an interplay of human and material conditions. Thus, we also paid attention to the material and symbolic artefacts that were embedded within descriptions of practice. Here we were concerned with the types of tools being used to manage the crisis, as well as the infrastructure that played a part in the way the crisis unfolded. Descriptions of coping and learning from the crisis were analyzed with reference to 'artefacts-in-practice' and included the influence of tangible material conditions (such as infrastructure, tools and machines) as well as less tangible elements (such as, processes, behaviours and concepts). In addition, as well as the testimony and descriptions of the events, we analyzed the specific recommendations from the Pitt report; using the same theoretical discourse we typed these 
data in terms of levels, social associations and artefacts-in-practice. Coding was initially done by hand, but later developed using NVivo software to allow a systematic categorization of data and the development of a thematic coding structure. Our analysis was iterative, evolving from existing theory, but developing through sensitivity to the data.

\subsection{Gloucestershire Floods2007: the Crisis}

Just four months after being awarded 'Beacon Status', on 20th July 2007 Gloucestershire suffered flooding reported to be the most serious in a hundred years. Following the crisis, Gloucestershire CC's senior BCM manager was moved to a new position. A subsequent public inquiry described the floods, which affected many parts of the UK, as the Country's largest peacetime emergency since World War II (Pitt, 2008). Emerging from a subsequent investigation (Garnham, 2007) were a number of serious concerns including lack of awareness of single points of failure within Gloucestershire's critical infrastructure and inadequate warning systems, amongst other issues.

Freak rainfall in Gloucestershire, and other parts of the UK triggered major disruption of road and rail networks, with 10,000 motorists stranded, over 6,000 homes and business premises flooded and entire communities inaccessible. More than 25,000 homes were without electricity for 48 hours and water supplies to 135,000 homes and 7,500 businesses were severed for approaching 12 days. After the shutdown of the Tewksbury treatment plant on 22 July, a further 350,000 were left without mains drinking water for over 20 weeks. Estimates suggest approximately $£ 25 \mathrm{M}$ was needed to repair flood-damaged roads. Three people died in the county and the demands of managing the event raised questions about Gloucestershire's preparedness, despite its earlier award of Beacon Status for its BCM processes. Subsequently, Gloucestershire CC commissioned its own inquiry, with the stated purposes of 'highlighting any contributory factors, beyond the exceptional weather conditions, that resulted in the flooding,' providing answers to questions raised by members of the local community and to ensure that it could provide a considered response to the Government's public inquiry (Garnham, 2007). A number of limitations of Gloucestershire's preparedness were identified. These included:

- Lack of consultation with key agencies in developing County's emergency plans.

- Vulnerable location of the Emergency Management Service Emergency Response Centre in an underground bunker that was prone to flooding. The Centre had to be relocated during the crisis event.

- Failure to identify single points of failure, such as water treatment works, and prioritise apt response.

- Poor communications from Gloucestershire CC with its staff, communities and partner authorities.

The Pitt Report, which included an analysis of all of the affected areas in the UK, included ninety two separate recommendations. Notable here are the poor quality of flood warnings, the lack of technical ability to manage flood risk, critical infrastructure failures that lead to the loss of essential services, and the lack of education and advice on how to protect homes and to recover from such a crisis. The data analysis below is organized into the four main categories identified in the data: context and infrastructure, artefacts-in-practice (including sensemaking and routines, as well as tools and technology) and the social associations and levels of interactions. 


\subsection{Context and Infrastructure}

In considering the context we noted two particular factors. The first is the general geographic and social context within which the region is located. These are the historical, social and geographic antecedents that contribute to the general vulnerability of the region to such an event. So, for example, the pressure on housing shortages since 1945 and, the practice of building new housing, businesses and infrastructure on flood plains, inevitably increased the risk of flood damage to property and utility services. Pitt (2008) cited a Foresight study (2004) predicting extremes in weather, especially rainfall, caused by global warming. Combined with the practice of home-owners concreting gardens, inadequate sewerage and drainage systems and saturated ground prevented surface water from discharging and further contributed to the likelihood of flood damage. That is, the vulnerability to flooding is part of the social, geographic and historical fabric of the region.

That said, it is notable in the data how, during this crisis event, critical single points of failure and inadequate infrastructure contributed to the difficulty in coping and recovery. For example, the closure, at Tewksbury, of a major water treatment plant interrupted supplies of fresh water for 20 weeks. Commenting on this issue, Head of Emergency Management Services notes:

'this water treatment plant supplies water to 350,000 people. It is the only means of supplying that distribution network and it's one of about 5 water treatment plants that Severn Trent operate that are single points of failure. We didn't know that. I should have known that, I didn't know that. The Civil Contingencies Act is very clear that the utility companies are responsible for their own emergency planning and they knew that that was a single point of failure'.

Additionally, a major power outage to 550,0000 people was narrowly avoided when the Walham substation managed to survive, but over 40,0000 homes and 7,500 businesses lost power when the Castle Meads substation shut down.

While the geographic limitations of the UK mean that it is inconceivable to ban building on flood plains, this does not mean that critical infrastructure cannot be better protected, or that single points of failure cannot be avoided, concluded Pitt (2008). Specific recommendations from Pitt (2008) included the removal of automatic connection to the existing sewerage system for surface water drainage and the banning of impermeable surfaces in gardens. Resilience and redundancy can be built into critical infrastructure through amended standards of construction, flood management measures and the development of business continuity practice to better manage risk. That is, learning can be reflected in changes to critical physical infrastructure that supports crisis management activity.

\subsection{Sensemaking: Routines, Norms and Behaviours}

Descriptions of events included in testimony by those dealing with the crisis suggested recourse to artefacts-in-practice such as standard practices and processes developed from previous experiences and/or codified in standard operating procedures and policies. That is, we noted how activities were influenced by past, even recent, events, and how symbolic artefacts are updated and evolve iteratively through learning from crisis, influencing the nature of future practices. For example, at the institutional level, the Pitt Report and the Garnham Report are themselves artefacts that captured past learning and seek to influence 
future practices by setting the scene and making recommendations for developing new routines, norms and behaviours, and these reports build on previous such events. However, this codified learning is immediately out-of-date, based, as it is, on a specific context. Noting that it is impossible to plan for every event, given the complexity of, as yet unforeseen circumstances, the Head of Emergency Management Services at GCC suggested:

\begin{abstract}
'emergency plans were like telephone directories, you put everything in there, nobody ever knew what was in there because they never sat and read them, and they weren't necessarily workable documents.... Now we've moved away from that and I think experience from 9/11, and please correct me if I'm wrong, but the overriding experience of 9/11 were companies saying their business continuity plans, the less detailed, more flexible plans actually were very effective and the very prescriptive plans just didn't even get off the ground. I think that was the experience'
\end{abstract}

In other words, policies, processes and routines provide a framework for action, but the actual practice evolves as those in charge or involved in circumstances make sense of the ambiguous information, confused circumstances and incomplete data with which they are faced. Weick's (1993) analysis of the collapse of sensemaking in the Mann Gulch fire highlighted the importance of preparation of team building activities to build organizational resilience by increasing the probability that constructive, informed interactions will occur amid agencies dealing with a major incident. However, in responding to flooding at the local level, in some areas 'there were no agreed protocols between responders' (Pitt, 2008: xxv). However, by the time of the Gloucester flood, experience from previous floods in Sheffield and Hull had highlighted the importance of securing a high level, co-ordinated response early. This has now been turned into a recommendation for future policy and crisis responses. In addition, while there was often a lack of clarity about who was responsible for coordinating flood rescue, or what roles particular agencies should take, experience at all three events demonstrated that the police were best placed to co-ordinate a multi-agency responses to such a crisis, and this has also been captured and recommended as a future routine action. Further, such 'normal' actions that were captured and recommended for future policy included multi-agency local resilience forums (to share expertise and experience) and prescribed levels of agency and business engagement in planning, exercising and response, including the implementation of enforcement strategies for participation.

Some tragedies were avoided when local level members of the public or emergency service personnel responded to particular events that they faced. Here we see particular examples of how local people, because of their knowledge and experience, and often because there was no one else to turn to, took action themselves to mitigate their own, and others' circumstances. Pitt notes that 'community action was one of the most striking impacts of the summer floods' (2008: xxxiv) and there were numerous stories in the press about how people coped and helped each other. These outcomes have also been captured and made into recommendations in the form of advice to the public on emergency flood kits and community support education programmes. Other norms captured included the importance of education and monitoring in response to the health risks posed by such an event. Other agencies, such as insurance companies also became heavily involved in the recovery. Here the experience is variable, depending on location and company, or insurance agent. Statistics showed 22 percent of those affected were dissatisfied with the performance of their insurance company. A number of recommendations thus also involve future policy for the provision of insurance and expectations about levels of service. 
What is striking is how practices and activities were influenced by past, even recent, events, and how symbolic artefacts were updated and evolved iteratively. However, we also note that behaviours, norms and practices emerged in context as people used past practice to make sense of, and manage, current events. Sometimes they were forced to be creative in order to develop solutions when previous experience failed or because the nature of such events makes outcomes unpredictable. Particular examples of community actions were striking in this regard. Available human and social capital was used to make sense of ambiguous circumstances and to develop practical solutions to problems that were faced, evident in practices by individuals and at the collective level. That is, it is practices, informed by existing norms, routines and policies that exemplify coping and learning in, from and for crisis. Sense is made of a particular set of circumstances drawing on past experience (albeit often in terms of existing policy or routines) but often this experience fails and actors are creative during the crisis. Learning from and for crisis attempts to capture that learning and codify it for the future, but this will only ever be partially successful.

\section{$5.3 \quad$ Tools: Managing Information and Responses}

A further category of artefacts-in-practice were the tools used in predicting and managing the crisis. Their use, or lack of use, influenced the nature and course of activity undertaken by individuals, emergency services, the council and businesses during, and in the recovery from, the crisis. So for example, the Pitt Report (2008) notes the lack of adequate warning systems to cover river and surface water flooding. He goes on to recommend the Environment Agency and Meteorological Office collaborate to develop the tools and techniques necessary to overcome this weakness and provide dynamic flood warning tools and modelling scenarios. However, it is also interesting to note that temporary flood defences were generally archaic, such as sandbags, when other more versatile, effective and more responsive measures are available, such as flood boards, air brick covers and other temporary defences. Knowledge of the availability of such tools and other technical systems that can manage infrastructure information, or map and visualize the flood's advance, was not readily available. This made it particularly difficult for emergency responders, as well as the public, to know how to cope during the crisis. Because information was dispersed between agencies, contained in specialist information systems, and there was at times too much uncollected information, responders were overwhelmed and found it difficult to collate, interpret and translate that information into action. Here, the same difficulties were apparent when providing information to the media and many residents in the area were caught out unawares. This confusion and lack of tools also lead to complaints from the public that advanced warning was not available, or if the internet was used to search for updates, the information was confusing and contradictory. As one member of the public noted:

'It happened really quickly, it just came. It was like a river coming down the street' (Pitt, 2008, ix)

In response, a recommendation to provide a more direct flood warning system, perhaps by telephone, was made, to ensure that information is disseminated to the public so that it can be used to take informed actions in response to an emerging crisis, and so that they are not caught unawares.

Other tools suggested throughout the Pitt report included: readily available and easily understandable information for house purchasers on flood risk; tools to monitor health and wellbeing and translate health risks into appropriate actions for the public; the development 
of technology and process improvements to speed up drying out and aid recovery; better weather forecasting and predicting technology; tools to map and assess risk for flood drainage; improve technical capabilities to deliver flood risk management responsibilities; and the implementation of a flood warning service to critical infrastructure operators so that longer lead times and details can be provided on the velocity and depth of flooding. In perhaps a 'catch all' recommendation Pitt (2008) simply recommends emergency responders should review the effectiveness of their response facilities, including flexible accommodation, IT and communications systems. In other words, new tools and technologies were considered essential to managing during, and recovering from, the crisis. Tools and technologies were deeply embedded in the decision making processes and informed the types of actions and practices that responders and the public enacted as they struggled to cope with the crisis they faced. Indeed, at times, coping and acting in response to the flooding was hampered by a lack of suitable tools to co-ordinate information and translate that into action in order to ensure an appropriate and timely response to emerging situations. Tools, then, are essential for coping during crisis and their development provides evidence of learning from crisis.

\subsection{Social Associations and Levels of Interaction}

What was particularly telling in accounts of the floods was the way the above artefacts-in-practice and the context and infrastructures created a landscape on which action was enacted, and how they provided the links and interactions between institutional layers. So, for example, the frameworks and policies already in place and suggested by 'best practice' within the Beacon award scheme should include the allocation of certain responsibilities and/or co-ordinating roles to different emergency responders and agencies. Indeed, embedded within the routines are protocols for levels of command to manage the response and recovery processes. Response frameworks, however, and the lack of clarity about who was responsible for flood rescue, were considered to have placed the public and the responders at some risk. This, it seems, is because the level of interaction and availability of information through appropriate technology was a point of weakness in the system and the infrastructure included single points of failure that exacerbated an already difficult situation.

In this regard, the findings and recommendations of the Garnham and Pitt Reports primarily indicate a number of infrastructure weaknesses, routines and norms and technologies to be adopted to manage future events. A number of these are primarily focused on informing decision-making and actions and their adoption will obviously change the social networks and levels of interaction between government, agencies and locals. In that way these new protocols, information campaigns, systems and mandatory requirements are the material that will encourage interactions between and within levels. The artefacts-in-practice that are available and will be developed in the future both frame and stabilize a particular set of connections, influencing how information can be translated into actions.

Existing technologies and sensemaking routines were inadequate to deal with the unfolding crises, leaving rescue organizations 'unclear about the roles each of the organizations and who was taking the lead' (Pitt, 2008: xxiv). As Pitt describes, this often left those at the local level and within agencies dealing with the events, but 'poorly integrated into the response effort' (ibid). While some ad hoc mutual arrangements worked well, this still demonstrates that practices evolved dependent on how responders, locals and voluntary aid agencies were connected into the response effort through infrastructure, technology and tools and their own social capital. Given these circumstances their ability to respond emerged out of their own experience, networks and local knowledge to develop plans of action. Stories 
in the newspapers recall several instances where local police officers, fire and rescue staff, and 'locals' used whatever resources they could find, such as inflatable dinghy's to rescue stranded residents, or recount tales of young people and voluntary agencies, such as the Salvation Army, setting up local aid centres for vulnerable people.

A few other examples of how particular artefacts, or the lack of them, translated into action include: a lack of knowledge about health risks resulted in teenagers 'body surfing' on what was, potentially, contaminated water; existing regulations stipulated that 10 litres of water should be supplied to affected members of the public, but this was woefully inadequate for dealing with longer-term needs, particularly for the vulnerable and sick; and the lack of a 'unifying act' that clearly articulated roles and responsibilities at all levels resulted in confusion amongst agencies about who was responsible for what in terms of flood management. As the Head of Emergency Management Services at GCC suggests:

\begin{abstract}
'You have got to have very distinct people doing the response, very distinct people doing business continuity and very distinct people doing recovery and you have got to have it that distinct otherwise people don't understand, they've got to talk to each other...but they've got to be distinct people so that the rest of the staff in the organisation know, ah, she's dealing with the response, she's going to Gold, he is looking after the business continuity...'
\end{abstract}

Commenting on the formal command structure, it was noted that lessons from previous floods were implemented in later events of that summer, with levels of command moving from local Silver levels to Gold, area wide, command centres at an earlier point in the event. This helped by connecting and co-coordinating information dissemination across a broader set of agencies allowing a more coherent response. This also allowed a more structured engagement with the media, as a warning system and news service, further disseminating information. Recommendations for the future in the Pitt reports suggest that this level of responsibility, and the wider network of interconnected actors and systems it facilitates, should be an immediate response, on a precautionary basis, to a predicted flood. Indeed, many of the recommendations that come from the Pitt and Garnham reports suggest that policies, protocols and systems of information flow and dissemination are essential to connect between responder agencies and to connect through the levels to the local communities. In doing so it is suggested that warnings, immediate responses and precautionary actions can be both measured and taken promptly. Indeed, a striking recommendation following the floods is the development of the role of Local Resilience Forums to evaluate and share lessons from both response and recovery phases of emergencies. That is, these forums are tasked with connecting to a number of co-ordinating agencies, volunteers and infrastructure providers both within and across authority areas.

\title{
6.0 Conceptualizing Recursive Learning from Crisis
}

From the analysis above, we can see that artefacts-in-practice and essential infrastructure create the landscape on which responses to crises are enacted. It is these objects or devices, as well as previous experience, which influence our sensemaking. They represent an accumulation of experience and understanding, stabilized into particular, routines, norms or technologies, which inevitably shape enactment. The actual routines and objects create connections between individuals, agencies and communities and they provide a template against which the complexity of organization is conducted. They are the system through which knowledge is translated between domains and they thus inform action. The artefacts-in- 
practice create a web of associations and interactions that fundamentally influence the outcome and unfolding of events.

There seems to be three important events shaping this translation into practice. First are the routines, policies, experiences or norms that shape the sensemaking strategies of those involved in the crisis. Here in the data we can see evidence of this prior learning being enacted and influencing action in response to the unfolding events. So, for example best practice, evident through such awards as 'Beacon Status' given to GCC as part of its preparation for business continuity management shape the way the Council prepared for and responded to the crisis. However, more dynamically, lessons were also learned from previous crises regarding the initiation of levels of command - Silver, Gold and COBR - that influence decisions during later floods, and which have now been made as recommendations to shape future policy. Second, the tools available to manage the unfolding events, such as weather monitoring, maps, flood defence equipments, health information and other emergency equipment, limited or influenced when and how emergency responders, and members of the public were able to implement timely and adequate responses to the emergency. So here we see that the lack of access to predictive forecasting, flood barrier equipment and appropriate information on health advice influenced the way people responded or were able to respond to the difficulties they face. So for example, the speed of the event caught many unaware and caused difficulties. Third, the actual infrastructure, such as power, roads, drainage, and water supplies, created the context within and against which these events occurred. Single points of failure, flooded transport routes and inadequate drainage systems, are part of the complex scenario which those operating in the crisis have to manage. Those coping with the crisis are operating in this complex material and symbolic world and operating, with their sensemaking resources, the tools at infrastructure at their disposal, to translate that into social practice. This sense of recursivity within which social activity takes place is conceptualized in Figure 1. Here we try to capture this dynamic and continually unfolding sense of practice, where those acting to cope with events are influenced by tools, sensemaking and infrastructure, which is translated into practice.

\section{<Insert Figure 2 Here >}

Institutional theory provides a useful perspective from which to reflect upon the establishment, dissemination and adherence to expected and legitimised standards of practice and organization. Central to institutional theory, suggested in Tolbert and Zucker's (1983) two stage process of diffusion, is with the shift from technically driven innovation to the pursuit, adoption, compliance or, 'more correctly' imitation of 'legitimised templates'. A focus on the field level, still largely neglected in studies of organizational learning from crisis, provides a basis for considering how the transfer of codified 'best practice' or 'lessons learned' may impede rather than necessarily aid an organization's response to crisis. Drawing from Schatzki (2005), efforts to use norms and rules defined previously may set the limits of what should be done. Attempts to put into practice lessons learned from previous crisis events take on meaning, fully, at the point when they are interpreted in an effort to make sense of a new situation and enacted in order to manage an emerging scenario. There is a sense of such norms and rules being applied rigidly. This may be seen as characteristic of crisis events, a view emphasised by Weick (1993) who observed at Mann Gulch that creativity is most unexpected in life threatening situations. For Weick (1993) the bricoleur, probably with much experience of acting in, and pulling order from, chaotic conditions, remain creative under pressure, and is a key source of organizational resilience. It is that sense of dynamic 'bricolage', which we suggest is evident in much of the learning that occurs 'in crisis' and which might shape learning 'from, and 'for' crisis, but is the very reason why routines, best practice and 
codified learning after crisis can never capture the complexity of events to ensure that 'this never happens again'.

Crisis events depend on those acting within them to retain flexibility and creativity in their translations into practice. Here we can also see in the data, that the tools, infrastructure and sensemaking strategies, not only translate individuals' and groups' responses into action, but that they also create the social associations and interactions through which the crisis is managed. Thus, we can see how the processes of coping with crisis, and learning in such an event, takes form as a result of association and relations constructed, in part at least, through these artefacts (Law, 1999). So not only is this translation into practice occurring within pockets of activity, these are connected through interaction within, and between, different locations. So for example, levels of responsibility influence the nature of responses in individuals and by different organizations; it also influences who will co-ordinate with whom. We can see in the data for example, that a lack of clarity of such levels of responsibility was seen to put emergency responders and members of public at risk; it also meant that emergency responders and members of the public had to act to mitigate events through their own ingenuity, opening flood centres, rescuing residents and collecting and distributing medicines to those in need. While this is an example of bricolage in action, it also shows how social actions and translation into practice at one level, interacts and shapes the translation into action at other levels and in other locations. This is represented in Figure 3. Finally, we should note that this crisis occurred in a specific context, one where climate change, population pressures, houses built on flood plains and underinvestment in infrastructure, have set the conditions for such a crisis to occur. Such events are part of the fabric of life, and will inevitably influence the nature of such an event occurring again in the future. These issues may never be resolved and as such are part of the existing socio-historic context which makes a crisis more, not less likely, and which makes learning, in, from and for crisis, so important.

\section{$<$ Insert Figure 3 Here>}

Existing artefacts, tools, norms and infrastructure will always be implicated in coping with crisis. Indeed, such crises bring them centre stage and makes them the 'object of activity' through which transformational learning occurs (Engestrom and Blackler, 2005). Inevitably, that learning will result in new artefacts, norms, routines and infrastructure that shapes future sensemaking and actions since they become part of the fabric on which organization occurs (Scahtzki, 2005). Artefacts, both symbolic and material, represent past learning, but they are also central to unfolding new processes and activities. (Knorr Cetina, 2001). However, when tools, devices, objects or artefacts create opportunities to invoke differences between communities, or are pliable enough to be used in a variety of contexts, there exists the potential for translation of understanding between different domains of practice (Star and Greisemer, 1989), and perhaps also the ability to use, modify and adapt such artefacts to unforeseen and unpredictable events. In learning from crisis, perhaps we need to be circumspect about the degree to which we embed that learning in rigid policy or infrastructures that might be designed to cope with past events, but do not allow the flexibility to cope with as yet unforeseen circumstances. Tools, infrastructure and sensemaking (such as broader experiences) that shape social practice need to provide the flexibility to cope with ambiguous and unfolding events. That may be just too unrealistic given the need to demonstrate what we have learned in concrete lessons in order to assuage concerns of the public. 


\subsection{Conclusion}

In Gloucestershire the available artefacts that have been developed, and will be developed in the future, frame and stabilize a particular set of connections. In this event, the data suggest a rigidity amidst a relatively inadequate response. Future crisis events are likely to occur within a distinct context and it is questionable that developments will be better suited to future conditions. Recommendations from the Pitt Report may be seen not only as an effort to achieve real learning, but also as the demonstration of Government dealing with the flooding crises appropriately. References to compliance with BS25999, a new Business Continuity Standard, which evaluates paper processes and systems, for example, suggest a focus upon legitimacy rather than upon changes to practice and attitudes. Such compliance will do little to enhance or develop the various sources of organizational resilience discussed by Weick (1993). Greater prescription is likely to hinder the emergence of bricolage. However, from our case bricoleurs were found amidst the emergency services staff and members of the public, who employed whatever resources they could to effect the rescue of stranded residents when existing technologies and routines proved inadequate to meet the demands of the crisis. Recommendations that outline distinct areas of responsibility suggest neat accountability, but not necessarily a basis for a creative and flexible response to an emerging crisis event.

Unless one is deliberately intent on nefarious deeds, intentional actions taken to manage and recover from a crisis can be assumed to have been taken with the best of intentions. Thus, when things are not perceived to have worked, the disappointing outcomes may be more to do with material arrangements, distributed practices, experiences and context, (such as infrastructure) available to cope with a given scenario, rather than the failure to adopt or define 'best practice', codified and copied from elsewhere. Learning in and from experience, prepares us only to replay what we have learned in order to make sense of and enact practice in a similar scenario, or to use that experience to make sense of unfolding events. It is only when a breakdown of coping occurs, when things do not go as intended, that we become aware of the inadequacy of our established practices (Chia and Holt, in press; Turner, 1976). That is not to say that learning lessons is not important. Rather, perhaps we should not be surprised when the lessons we have learned fail to prepare us for unforeseen and unpredicted events, or even when, in similar circumstances, but with different technologies or people involved, outcomes during and after crises are disappointing. 


\section{References:}

Antonacopoulou, E. (2008) On the Practise of Practice: In-Tensions and Ex-Tensions in the Ongoing Reconfiguration of Practices. Handbook of New and Emerging Approaches to Management and Organization. D. Barry and H. Hansen, Sage.

Bechky, B. A. (2003) 'Sharing Meaning across Occupational Communities: The Transformation of Understanding on a Production Floor.' Organization Science 14(3): 312330 .

Birkland, T (2006) Lessons of Disaster, Washington: Georgetown University Press

Birkland, T. (1997) After Disaster: Agenda Setting, Public Policy, and Focusing Events.Washington. Georgetown University Press.

Boin, A., McConell, A. and t'Hart, P.(eds) Governing After Crisis Cambridge : Cambridge University Press

Callon, M. (1999) Actor-Network Theory-the Market Test. Actor Network Theory and After. J. Law and J. Hassard. Oxford, Blackwell: 181-195.

Carlile, P. R. (2002) 'A Pragmatic View of Knowledge and Boundaries: Boundary Objects in New Product Development.' Organization Science 13(4): 442-455.

Carroll, J S., Rudolph, J W and Hatakeneka, S. (2002) Learning from experience in highhazard organizations Research In Organizational Behaviour, 24 pp 87 -137

Child, J. (1972) 'Organizational Structure, Environment and Performance: The Role of Strategic Choice.' Sociology 6: 1-22.

Cohen W.M. and Levinthal, D.A. (1990) Absorptive Capacity: A New Perspective on Learning and Innovation, Administrative Science Quarterly 35, pp128-152

Crossan, M. M., Lane H. W. and White R. E. (1999) 'An Organizational Learning Framework: From Intuition to Institution, Academy of Management Review 24 (3) pp 522537.

Di Maggio P. J., and Powell, W. (1983) The iron cage revisited" institutional isomorphism and collective rationality in organizational fields", American Sociological Review, 48, 14760 .

Drori, G. S. and Meyer, J. W. (2006) Global Scientization: An Environment for Expanded Organization in Drori, G. S. and Meyer, J. W. and Hwang, H (eds) Globalization and Organization: World Society and Organizational Change Oxford, Oxford University Press

Drori, G. S. and Meyer, J. W. and Hwang, H (eds) Introduction Globalization and Organization: World Society and Organizational Change Oxford, Oxford University Press

Elliott, D and Smith, D (2006) 'Patterns of Regulatory Behaviour in the UK Football Industry' Journal of Management Studies, 43 (2) pp 291- 319 
Elliott, D (2008) Modelling Learning from Crisis Proceedings of the British Academy of Management, Harrogate, September

Engeström, Y. and Blackler, F. (2005) 'On the Life of the Object.' Organization 12(3): 307330.

Greenwood, R; Oliver, C; Sahlin, K and Suddaby, R (2008) The SAGE Handbook of Organizational Institutionalism, London: SAGE

Haunschild, P. and Chandler, D. (2008) Institutional-Level Learning: Learning as a Source of Institutional Change in Greenwood, R, Oliver, C, Sahlin, K and Suddaby, R (2008) The SAGE Handbook of Organizational Institutionalism Los Angeles; SAGE

Jones, B and Cox, S. (2005) Organizational Learning within High Reliability Organizations can we afford not to?

Kellogg, K. C. (2006) 'Life in the Trading Zone: Structuring Co-Ordination across Boundaries in Postbureaucratic Organizations.' Organization Science 17(1): 22-44.

Knorr Cetina, K. (1999) Epistemic Cultures: How the Sciences Make Knowledge. Cambridge, Massachusetts, Harvard University Press.

Knorr Cetina, K. (2001) Objectual Practice. The Practice Turn in Contemporary Theory. T. Schatzki, K. Knorr-Cetina and E. Von Savigny. London, Routledge: 175-188.

Lampel J. and Meyer, A. D. (2008) Field-Configuring Events As Structuring Mechanisms: How Conferences, Ceremonies and Trade Shows Constitute New Technologies, Industries and Markets, Journal of Management Studies, 456 pp1025-1035

Latour, B. (1999) Pandora's Hope: Essays on the Reality of Science. Cambridge, MA, Harvard University Press.

Lounsbury, M. (2007) A Tale of Two Cities: Competing Logics and Practice Variation in the Professionalizing Of Mutual Funds, Academy of Management Review 50: 2 289 -307

Love, E. G. and Cebon, P. (2008) Meanings on Multiple Levels: The Influence of Field-Level and Organizational- Level Meaning Systems on Diffusion, Journal of Management Studies 45: 2 239- 267

May, P. J. (1992) Policy Learning and Failure Journal of Public Policy, Vol. 12, No. 4. (Oct. Dec.), pp. 331-354.

Power, M (1997) The Audit Society: Rituals of Verification Oxford ; Oxford University Press

Power, M (2007) Organized Uncertainty: Designing a World of risk Management Oxford Oxford University Press

Orlikowski, W. (2002) 'Knowing in Practice: Enacting a Collective Capability in Distributed Organizing.' Organization Science 13(3): 249-273.

Orlikowski, W. J. (2000). Using Technology and Constituting Structures: A Practice Lens for Studying Technology in Organizations. Organization Science. 11: 404-428. 
Scarbrough, H., Swan, J., Laurent, S., Bresnen, M., Edelman, L. and Newell, S. (2004) 'Project-Based Learning and the Role of Learning Boundaries.' Organization Studies 25(9): 1579-1600.

Schatzki, T. (2005) 'The Sites of Organizations.' Organization Studies 26(3): 465-484.

Schein, E.H. (1985) Organizational Culture and Leadership. San Francisco: Jossey-Bass.

Smith, D and Elliott, D (2007) Exploring the Barriers to Learning from Crisis, Management Learning, Vol. 38, No. 5, 519-538

Star, S. L. and Greisemer, J. R. (1989) 'Institutional Ecology, 'Translations' and Boundary Objects: Amateurs and Professionals in Berkely's Museum of Vertebrate Zoology, 1907-39.' Social Studies of Science 19(3): 387-420.

Taylor, J. R. and Robichaud , D. (2004) 'Finding the Organization in Communication: Discourse as Action and Sensemaking.' Organization 11(3): 395-413.

Tolbert, P S and Zucker, L. G. (1983) 'Institutional sources of change in the formal structure of organizations: the diffusion of civil service reform, 1880-1935.', Administrative Science Quarterly, 28: 22-39.

Turner B A and Toft, B (1988) 'Causes of Disaster: Sloppy Management', British Journal of Management Volume 5 Issue 3: 215-219.

Weick, K. (1988) 'Enacted Sensemaking in Crisis Situations.' Journal of Management Studies 25(4): 305-317.

Weick, K. (1995) Sensemaking in Organizations. Thousand Oaks, CA, Sage.

Weick, K. E. (1993) The Collapse of Sensemaking on Organizations: The Mann Gulch Disaster Administrative Science Quarterly, 38 628-652

Wiseman, E. (2007) The institutionalisation of organizational learning: a neoinstitutional perspective. Proceedings of the Organizational learning and knowledge conference Learning Fusion pp. 1112 - 1135

Zilber, T. B. (2002) Institutionalization as an interplay between actions, meanings, and actors: the case of a rape crisis centre in Israel, Academy of Management Journal 45(1) pp $234-254$ 


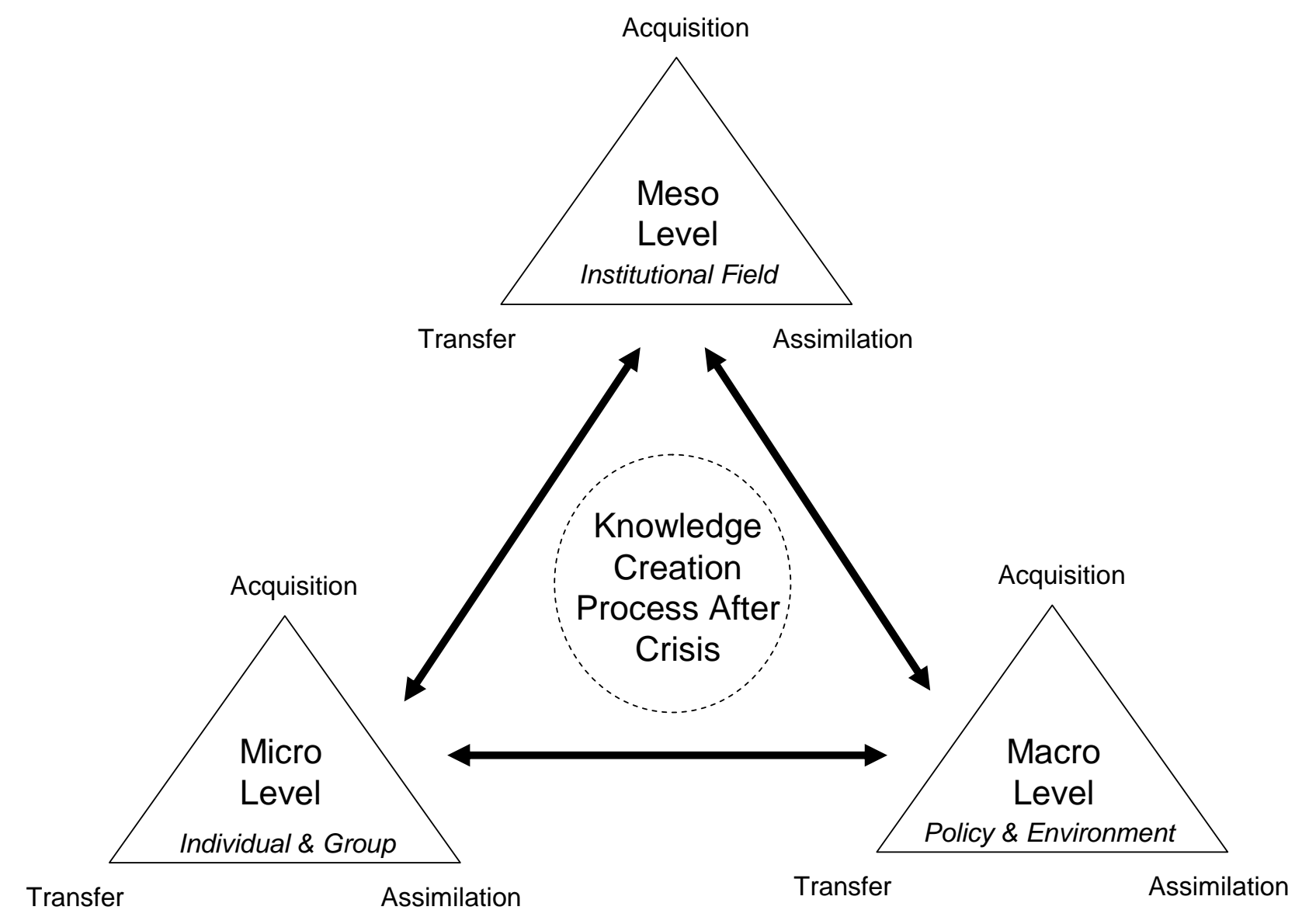

Figure 1. Knowledge Creation Process After Crisis 


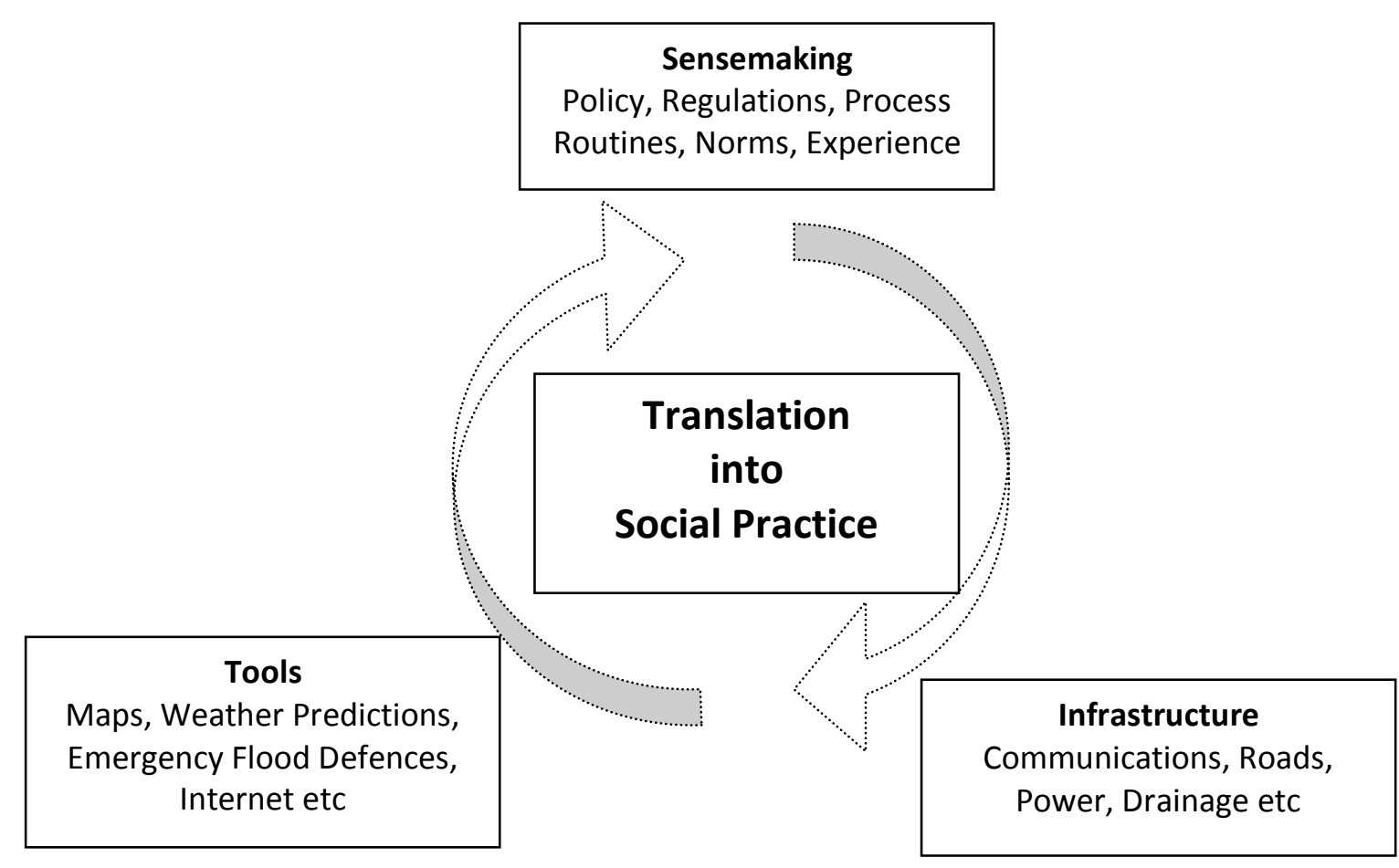

Figure 2. Recursive Learning In Crisis 


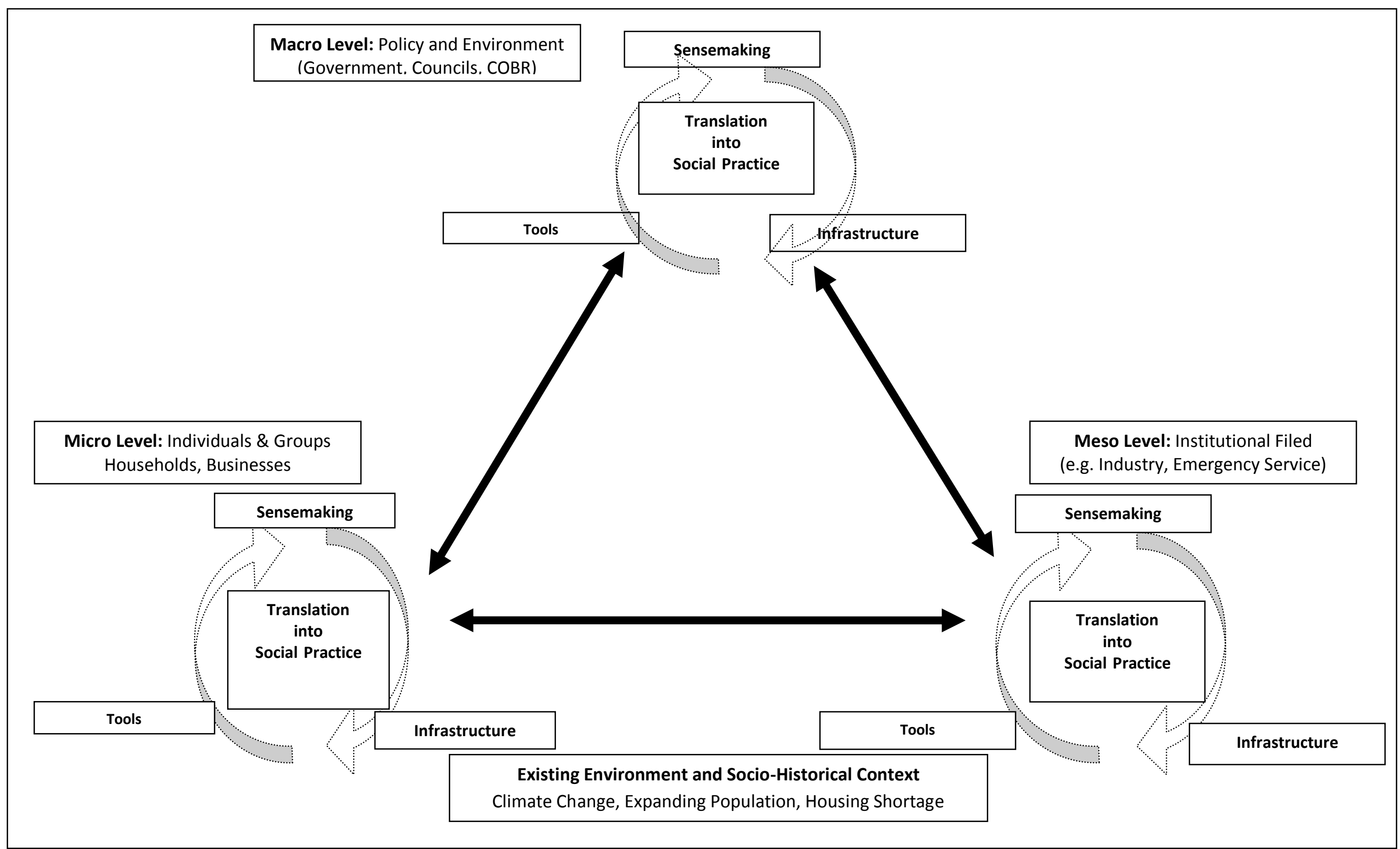

Figure 3.Interacting and Learning in Crisis 